\section{Psychological Medicine}

cambridge.org/psm

\section{Correspondence}

Cite this article: Vadhan NP, Corcoran CM, Keilp JG, Haney M (2019). Correspondence on Curran et al. (2018): 'Which biological and selfreport measures of cannabis use predict cannabis dependency and acute psychotic-like effects'. Psychological Medicine 49, 1227-1228. https://doi.org/10.1017/S0033291718004178

Received: 14 December 2018

Revised: 18 December 2018

Accepted: 19 December 2018

First published online: 29 January 2019

Author for correspondence:

Nehal P. Vadhan, E-mail: nvadhan@northwell. edu

\title{
Correspondence on Curran et al. (2018): 'Which biological and self-report measures of cannabis use predict cannabis dependency and acute psychotic-like effects'
}

Nehal P. Vadhan ${ }^{1}$, Cheryl M. Corcoran², John G. Keilp ${ }^{3}$ and Margaret Haney ${ }^{3}$

${ }^{1}$ Departments of Psychiatry and Molecular Medicine, Hofstra Northwell School of Medicine and the Center for Psychiatric Neuroscience, Feinstein Institute for Medical Research, Manhasset, NY, USA; ${ }^{2}$ Department of Psychiatry, Icahn School of Medicine at Mount Sinai, New York, NY, USA and ${ }^{3}$ Department of Psychiatry, Columbia University Medical Center and the New York State Psychiatric Institute, New York, NY, USA

To the Editor:

The interactions between cannabis use, use disorder and psychosis is an important topic that is worthy of systematic investigation. Therefore, we read with great interest our colleagues' article 'Which biological and self-report measures of cannabis use predict cannabis dependency and acute psychotic-like effects', recently published in Psychological Medicine (Curran et al., 2018). Within the framework of this otherwise well-conducted study, we respectfully suggest that accounting for the participants' predisposition to psychosis in the study methodology would have strengthened the findings.

The investigators employed a series of clinical and biological measures in the context of participants' (verified) naturalistic use and nonuse of cannabis, and found that: (1) cannabis intoxication increased the level of psychotic-like symptoms overall, and (2) evidence of greater recent delta-9-tetrahydrocannabinol $(\Delta 9-\mathrm{THC})$ exposure was associated with decreased psychotic-like effects of, but greater dependency, on cannabis. Essentially, while cannabis may have acute psychotic-like effects, more experience with cannabis is associated with lower psychotic-like effects but a greater likelihood of cannabis dependence. While this is a reasonable and well-supported conclusion, and the study had many methodological strengths, the investigators neglected to address a potential major factor in the acute psychotic-like effects of cannabis - namely, the predisposition to psychosis.

A substantial literature, employing a variety of methodologies and populations, has examined the psychotic-like sequelae of cannabis in the broad psychosis spectrum. Naturalistic/clinical studies have demonstrated that cannabis use is concurrently and prospectively associated with increases in psychotic-like experiences/symptoms in such individuals (e.g. Verdoux et al., 2003; Henquet et al., 2004; Hides et al., 2006; Corcoran et al., 2008; Henquet et al., 2010). Further, placebo-controlled drug administration studies have shown, compared to healthy cannabis users, evidence consistent with a stronger psychotic-like effect of (or psychosis-associated neurochemical response to) active cannabis $/ \Delta^{9}$-THC in individuals at genetic (Henquet et al., 2006), familial (Kuepper et al., 2013), clinical (Vadhan et al., 2017), or realized (D’Souza et al., 2005; Henquet et al., 2006; Kuepper et al., 2013) risk for a psychotic disorder. Finally, naturalistic studies have converged on these findings of differential effects (Henquet et al., 2010; Spriggens and Hides, 2015) and prospective cohort observation studies have provided further clinical significance (McHugh et al., 2017).

Although it could be argued that such populations were outside the scope of the Curran et al. (2018) study, individuals who have psychotic-like experiences are overrepresented in the cannabis-using population (van Os et al., 2008), and about $20 \%$ of individuals from our extensive database of nontreatment-seeking cannabis users endorsed having CHR-level psychotic-like experiences (unpublished data) on a screening questionnaire (Miller et al., 2004). This suggests the presence of a subpopulation of, at minimum, psychosis-prone individuals within the larger population of nontreatment-seeking cannabis users. If it is possible for the investigators to identify these individuals within their study (perhaps by the baseline Brief Psychiatric Rating Scale measures), a series of interesting analyses could be accomplished. For example, the notion that cannabis' psychotic-like effects are stronger in psychosis-predisposed individuals could be tested, and the similarities and differences in the interrelationships between previous cannabis exposure, dependency and psychotic-like effects, between these cannabis user subtypes could be assessed.

Author ORCIDs. (DD Nehal P. Vadhan, 0000-0003-0162-4256. 


\section{References}

Corcoran CM, Kimhy D, Stanford A, Khan S, Walsh J, Thompson J, Schobel S, Harkavy-Friedman J, Goetz R, Colibazzi T, Cressman V and Malaspina D (2008) Temporal association of cannabis use with symptoms in individuals at clinical high risk for psychosis. Schizophrenia Research 106, 286-293.

Curran HV, Hindocha C, Morgan CJA, Shaban N, Das RK and Freeman TP (2018) Which biological and self-report measures of cannabis use predict cannabis dependency and acute psychotic-like effects? Psychological Medicine 4, 1-7.

D'Souza DC, Abi-Saab WM, Madonick S, Forselius-Bielen K, Doersch A, Braley G, Gueorguieva R, Cooper TB and Krystal JH (2005) Delta-9-tetrahydrocannabinol effects in schizophrenia: implications for cognition, psychosis, and addiction. Biological Psychiatry 57, 594-608.

Henquet C, Krabbendam L, Spauwen J, Kaplan C, Lieb R, Wittchen HU and van Os J (2004) Prospective cohort study of cannabis use, predisposition for psychosis, and psychotic symptoms in young people. British Medical Journal 330, 11.

Henquet C, Rosa A, Krabbendam L, Papiol S, Fananás L, Drukker M, Ramaekers JG and van Os J (2006) An experimental study of catecholo-methyltransferase Val158Met moderation of delta-9-tetrahydrocannabinol-induced effects on psychosis and cognition. Neuropsychopharmacology 31, 2748-2757.

Henquet C, van Os J, Kuepper R, Delespaul P, Smits M, Campo JA and Myin-Germeys I (2010) Psychosis reactivity to cannabis use in daily life: an experience sampling study. British Journal of Psychiatry 196, 447-453.
Hides L, Dawe S, Kavanagh DJ and Young RM (2006) Psychotic symptom and cannabis relapse in recent-onset psychosis. Prospective study. British Journal of Psychiatry 189, 137-143.

Kuepper R, Ceccarini J, Lataster J, van Os J, van Kroonenburgh M, van Gerven JM, Marcelis M, Van Laere K and Henquet C (2013) Delta-9tetrahydrocannabinol-induced dopamine release as a function of psychosis risk: 18F-fallypride positron tomography study. PLoS ONE 8, e70378.

McHugh MJ, McGorry PD, Yung AR, Lin A, Wood SJ, Hartmann JA and Nelson B (2017) Cannabis-induced attenuated psychotic symptoms: implications for prognosis in young people at ultrahigh risk for psychosis. Psychological Medicine 47, 616-626.

Miller TJ, Chicchetti DV, Markovich PJ, McGlashan TH and Woods SW (2004) The SIPS screen: a brief self-report screen to detect the schizophrenia prodrome. Schizophrenia Research 70, 78.

Spriggens L and Hides L (2015) Patterns of cannabis use, psychotic-like experiences and personality styles in young cannabis users. Schizophrenia Research 165, 3-8.

Vadhan NP, Corcoran CM, Bedi G, Keilp JG and Haney M (2017) Acute effects of smoked marijuana in marijuana smokers at clinical high-risk for psychosis: a preliminary study. Psychiatry Research 257, 372-374.

van Os J, Linscott RJ, Myin-Germeys I, Delespaul P and Krabbendam L (2008) A systematic review and meta-analysis of the psychosis continuum: evidence for a psychosis proneness-persistence-impairment model of psychotic disorder. Psychological Medicine 39, 179-195.

Verdoux H, Gindre C, Sorbara F, Tournier M and Swendsen JD (2003) Effects of cannabis and psychosis vulnerability in daily life: an experience sampling test study. Psychological Medicine 33, 23-32. 